\title{
A POLÍCIA BIOECONÔMICA: O DISPOSITIVO POLICIAL NO CASO DAS UNIDADES PARANÁ SEGURO
}

\section{Murilo Duarte Costa Corrêa ${ }^{1}$}

\author{
Karoline Coelho de Andrade e Souza ${ }^{2}$
}

\section{Resumo}

Este artigo discute a polícia como dispositivo de poder bioeconômico. Para tanto, propõe analisar o caso das Unidades Paraná Seguro em Curitiba, Paraná, entre os anos de 2012 e 2015, com base em fontes documentais, investigando os limites analíticos dos policing studies, cuja inspiração weberiana resulta em uma compreensão da polícia sob seu aspecto exclusivamente repressivo. Uma análise mais detalhada das UPS - programa paranaense de policiamento comunitário que instrumentalizava a implementação de políticas socioeconômicas - descerrou uma forma de exercício de poder não-repressiva, mas constitutiva, como lógica do dispositivo policial. No caso analisado, a atuação da polícia articulava-se com a reconfiguração social e metropolitana do trabalho em Curitiba, implicando novos funcionamentos de poder, característicos do modelo biocapitalista e das sociedades de controle. Os achados empírico-documentais, avaliados na chave teórica da biopolítica foucaultiana, e de alguns de seus desdobramentos posteriores, permitiram redefinir a polícia como um dispositivo de poder bioeconômico, voltado para a gestão e a produção social da vida nas metrópoles.

Palavras-chave: Polícia. Bioeconomia. Biocapitalismo. Sociedades de controle. Unidades Paraná Seguro.

\section{CONSIDERAÇÕES INICIAIS}

Este artigo discute a atuação bioeconômica da polícia a partir da análise do programa de policiamento comunitário "Unidades Paraná Seguro (UPS)", instalado na cidade de Curitiba, capital do Estado do Paraná, durante os anos de 2012 a 2015, com o objetivo de desvendar a lógica de funcionamento do dispositivo policial. O programa integrou uma política de segurança pública, "Paraná Seguro", lançada pelo governo estadual, e tinha como principal objetivo reduzir os índices de criminalidade - em especial os homicídios - nos perímetros urbanos mais violentos e, conjuntamente, desenvolver ações de fomento à cidadania nas comunidades por meio de atividades e programas socioeconômicos.

\footnotetext{
${ }^{1}$ Professor Adjunto de Teoria Política da Faculdade de Direito e do Programa de Pósgraduação em Ciências Sociais Aplicadas da UEPG, instituição em que coordena o LABTESP Laboratório de Pesquisa Interdisciplinar em Teoria Social/Teoria Política e PósEstruturalismo. Affiliated researcher da Faculty of Law and Criminology da Vrije Universiteit Brussel, onde real izou estágio de pós-doutorado. Doutor (USP) e Mestre (UFSC) em Filosofia e Teoria Geral do Direito. Universidade Estadual de Ponta Grossa, Paraná. Brasil. E-mail: mdc.correa@gmail.com ${ }^{2}$ Pesquisadora do LABTESP - Laboratório de Pesquisa Interdisciplinar em Teoria Social/Teoria Política e PósEstruturalismo ligado ao Programa de Ciências Sociais Aplicadas da Universidade. Estadual de Ponta Grossa, Paraná. Brasil. E-mail: kcasouza@yahoo.com.br
} 
O Programa foi deflagrado por uma iniciativa conjunta entre a Secretaria de Segurança Pública Estadual (SESP), a Polícia Militar do Paraná e a Secretaria de Justiça, Trabalho e Direitos Humanos (SEJU). Inspiradas pelo caso das Unidades de Polícia Pacificadora no Rio de Janeiro, as UPSs paranaenses foram concebidas como bases da Polícia Militar descentralizadas que receberiam um contingente policial específico para realização do policiamento comunitário, que consiste em uma forma de policiar voltada para a prevenção do crime, cuja execução exige uma ativa participação comunitária.

Para descrever o dispositivo policial sob análise a partir dos discursos e práticas envolvidos na execução desse programa, realizamos uma pesquisa qualitativa de base descritiva, lastreada no estudo de caso das 10 (dez) Unidades Paraná Seguro instaladas na cidade de Curitiba entre os anos de 2012 e $2015^{3}$, ano em que o programa foi descontinuado. As principais fontes de evidência do estudo têm natureza documental, como o arcabouço jurídico que envolveu o programa (leis, decretos e normativas internas da Polícia Militar), relatórios elaborados pela PMPR e pela SEJU, literatura especializada sobre policiamento comunitário e atuação policial, além do referencial teórico pós-estruturalista.

O primeiro tópico do artigo adota os policing studies como matriz teórica de primeira hora. Os policing studies constituem um importante marco teórico, originário dos Estados Unidos, e que goza de reconhecimento internacional. Reúnem estudos de natureza sociológica - como os de Egon Bittner e Jerome H. Skolnick - que, em regra inspirados pela sociologia weberiana, dedicam-se à análise de casos de corporações policiais específicas, definindo o que é a polícia e como ela atua.

Seguindo suas articulações na condição de a priori analítico, a primeira parte do texto dedica-se a inventariar as principais definições dadas à polícia pelos teóricos dos policing studies. Geralmente baseados na definição dada por Egon Bittner na década de 1960, a polícia aparece definida como um instrumento do monopólio estatal da violência. Os autores, embora reconheçam as diversas formas de atuação da polícia e proponham novos modelos, como é o caso do policiamento comunitário, permanecem atrelados ao horizonte weberiano clássico, mesmo que no campo das práticas sociais efetivas, a polícia tenha sofrido verdadeiras transformações.

Nas Unidades Paraná Seguro, verificou-se a sobreposição entre práticas de policiamento comunitário, recenseamento estatístico ${ }^{4}$ e atividades relacionadas a políticas públicas de natureza socioeconômicas. Isso conduz à hipótese, corroborada pelos achados empírico-documentais, de que

\footnotetext{
${ }^{3} \mathrm{Na}$ ordem em que foram inauguradas, as UPS analisadas foram: UPS-Uberaba, UPS-Parolin, UPS-Vila Sabará, UPS-Vila Verde, UPS-Vila Nossa Senhora da Luz e UPS-Vila Caiuá, UPS-Vila Osternack, UPS-Vila Sandra, UPS-Vilas Ludovica, UPS-Vila Trindade e, sem comprovação oficial, apesar de aparecer em alguns relatórios, a UPS-Vila Torres.

${ }^{4}$ Antes da instalação das Unidades, os policiais militares realizaram um reconhecimento criminológico, urbanístico e socioeconômico das áreas afetadas.
} 
as UPSs - expressões de um novo modelo de segurança pública e de atuação policial - implicam um dispositivo policial situado em um horizonte biopolítico. Isso corresponde a uma mutação explícita da lógica de policiamento nas sociedades de controle de economia biocapitalista. Eis o contexto em que os policing studies mostram-se parcialmente inadequados, especialmente para explicar a relação instrumental entre o dispositivo policial (suas práticas e discursos) e as dimensões contemporâneas do capitalismo metropolitano.

Por isso, a segunda seção do texto dedica-se à relação entre polícia e biopolítica, no contexto das sociedades de controle e do biocapitalismo, a partir do entrecruzamento das obras de Michel Foucault, Gilles Deleuze, Maurizio Lazzarato, Antonio Negri, Michael Hardt, Franco Berardi e Giuseppe Cocco. A revisão dessa literatura em particular permitirá redescobrir a vocação congenitamente biopolítica da instituição policial; sua gênese, no limiar da Modernidade europeia, evidencia que o conjunto de práticas, ações e mecanismos originariamente definidos como "policiais" tinha pouca relação com a atividade repressiva, sendo melhor definida como um dispositivo na gestão de populações.

No entanto, a polícia não é um dispositivo explicável exclusivamente por sua estrutura originária. $\mathrm{O}$ caráter híbrido das instituições policiais tanto permite que elas possam tomar parte em estratégias hegemonizadas pela violência repressiva e necropolítica (a que chamamos "polícia soberana") como em estratégias de gestão de populações (a polícia bioeconômica).

Esse deslocamento estratégico das polícias parece ressoar uma série de transformações econômicas e sociais ocorridas a partir da segunda metade do século XX. Esse novo contexto, em que as relações de produção são progressivamente recentradas no trabalho imaterial, implica que as formas de controle das populações sofram transformações correlatas, caracterizadas pela generalização dos mecanismos de controle e gerenciamento populacional.

O estudo de caso das UPSs de Curitiba favorece a visibilidade desse fenômeno: o advento de uma polícia que, apesar de não abandonar suas bem conhecidas práticas necropolíticas, não está reduzida a elas, e passa a atuar em um horizonte que, se não é inédito, exige estratégias de controle adaptadas aos novos termos da relação entre capitalismo pós-fordista, ou cognitivo, e trabalho imaterial ou biopolítico. Essa transformação é analisada com maior detalhe na terceira seção do artigo, sobretudo a partir dos trabalhos de Cristian Laval, Pierre Dardot, Franco Berardi, Maurizio Lazzarato e Giuseppe Cocco. No Brasil, os mais recentes ciclos de desenvolvimento econômico e os padrões sociais de produção e consumo que definiram a assim chamada "nova classe média"5

\footnotetext{
${ }^{5}$ Tese de Marcelo Neri (2010) para explicar a emergência de uma nova classe social, historicamente marginalizada, que, a partir das políticas sociais de emprego e renda dos anos Lula, começa a ascender socioeconomicamente. Esse fenômeno foi debatido, entre outros, por Marcio Pochmann (2012) e rebatizado muitas vezes como "batalhadores" (SOUZA, 2012), "precariado" (BRAGA, 2014) e "cognitariado" ou "multidão de pobres" (COCCO, 2014). Para Giuseppe Cocco $(2014$, p. 165), aliás, “[...] no plano material não há nenhuma classe média.
} 
integraram-na às malhas da economia de capital. As UPSs implicam que essa reconfiguração social esteja entrelaçada com o trabalho policial, na medida em que a polícia passa a atuar como um agente bioeconômico que catalisa, incentiva, estimula e opera processos de inclusão subordinada da multidão de pobres.

As Unidades Paraná Seguro implicaram o uso da violência característico da polícia, no clássico sentido dos polincing studies, por meio das operações de congelamento, por exemplo; no entanto, são os funcionamentos policiais que excedem a estratégia repressiva, revelando-se de gestão de populações, é que demonstram seu papel bioeconômico. A política pressuposta pelo programa Paraná Seguro não invalida a descrição das polícias como agentes da violência estatal supostamente legítima, mas exige que o dispositivo policial seja descrito em termos mais heterogêneos; como polícia bioeconômica, segundo um agenciamento concreto que transforma a polícia em um agente de gestão e produção da vida social, e de sua integração subordinada ao capital.

\section{A POLÍ́CIA NOS POLICING STUDIES}

Os policing studies, ou estudos de policiamento, constituem um dos campos teóricos mais produtivos nos contornos da sociologia. Eles derivam de um grupo de estudos nascido na década de 1960 nos Estados Unidos, centrado em autores que, em regra, possuem ligação direta com a polícia americana, e que busca analisar a história, a forma de funcionamento (princípios, técnicas, estratégias) e a definição de polícia, normalmente analisando casos de corporações reais. De acordo com Moore (2003), pode-se falar em três tradições distintas nesses estudos. A primeira tradição, da qual fazem parte autores como Egon Bittner e Jerome H. Skolnick, reúne os estudos sobre cultura organizacional e procura explicar o comportamento policial expondo fatos históricos, políticos, sociais e organizacionais. A segunda tradição baseia-se em métodos científicos que buscam avaliar os impactos das operações policiais em seus objetivos; por fim, a terceira via, integrada por Herbert Goldstein, volta-se para aspectos organizacionais e administrativos da polícia.

A recepção dos policing studies no Brasil deu-se a partir da década de 1980, em razão do movimento de redemocratização do país e, também, devido à tradução de muitas das obras desses autores ter sido realizada pelo Núcleo de Estudos da Violência da Universidade de São Paulo (NEVUSP). Embora sejam autores extremamente heterogêneos, possuem um fio condutor comum: seu vínculo com a sociologia de Max Weber e a adesão à sua definição de Estado como um agrupamento

É a composição de um novo tipo de trabalho, que acontece dentro e fora do emprego, nas redes sociais e de transportes, e tem nas universidades, escolas, museus, serviços e até nas reservas indígenas as suas novas fábricas". 
de dominação que detém o monopólio da força física legítima. Isso trará consequências imediatas sobre sua forma de imaginar, conceptualizar e analisar a polícia.

Para analisar o Estado, Weber (2004) adota como premissa a racionalização moderna que, de forma esquemática, compreende quatro traços característicos: (1) a burocratização do Estado em sentido positivo, como quadro administrativo racional, (2) assentado sobre normas jurídicas igualmente racionalizadas e especializadas, (3) o monopólio do poder, entendido em seu sentido negativo, como monopólio da coação física (violência), (4) legitimado pela submissão da conduta de seus agentes às normas jurídicas no interior de um determinado território. Contudo, a definição sociológica de Weber assenta-se, essencialmente, na característica peculiar ao Estado e a todo agrupamento político: o monopólio legítimo do uso da coerção física (WEBER, 1972).

Isso torna possível que as pesquisas dos policing studies, situadas majoritariamente entre as décadas de 1960 e 1970 - como é o caso do Jerome H. Skolnick, de Justice whithout trial (1966), ou de Herman Goldstein, com Policing a free society (1977) -, não problematizem a definição de polícia, mas invistam sobre questões da prática policial e seus desafios. Skolnick (2011 [1966]), ao invés de definir a polícia, torna sua existência problemática a partir do dilema entre lei e ordem, tendo em vista o perene mandato de manutenção da ordem; Goldstein (2003 [1977]) volta-se para a teorização da discricionariedade como um dos aspectos fundamentais que envolvem a prática policial.

Caberá a Egon Bittner, em The functions of the police in modern society (1970), expor os pressupostos weberianos dos policing studies, sustentando que a polícia é antes de tudo um instrumento para o uso da força física. Para ele (1970, p. 46): “[...] o papel da polícia é melhor entendido como um mecanismo para a distribuição de força coercitiva não-negociável empregada de acordo com os ditames de uma compreensão intuitiva das exigências situacionais" ${ }^{\text {"6 }}$. Dessa forma, ela estaria autorizada a intervir em todas as situações em que o uso da força torne-se necessário para garantir a ordem, e sua legitimidade decorreria da própria situação de necessidade.

A maneira como Bittner define a polícia baseia-se, portanto, não só na ideia de que a polícia é um mecanismo aplicador da violência, como a legitima no Estado, especialmente por meio das noções de ordem e de necessidade. Ele compreende que mesmo que um policial não faça o uso da coerção física, está virtualmente autorizado a fazê-la, e sendo ele designado para manter a ordem, caso seja necessário, de acordo com as situações - normalmente quando ele é chamado para agir coercitivamente -, poderá aplicar essa força.

\footnotetext{
${ }^{6} \mathrm{Em}$ tradução livre do original: "[...] the role of the police is best understood as a mechanism for the distribution of non-negotiably coercive force employed in accordance with the dictates of an intuitive grasp of situational exigencies".
} 
Em 1990, Egon Bittner lançou Aspects of police work, uma coletânea de textos que representava uma espécie de "balanço" de seus 25 anos de produção acadêmica. Nessa coletânea, evidenciam-se as modificações da polícia, como é o caso das iniciativas do policiamento orientado para solução de problemas (POP), desenvolvido por Goldstein, e do policiamento comunitário. Nele, uma de suas preocupações é definir a função policial como "aplicação da lei”, enfatizando a profissionalização e racionalização da atividade policial, para além do mandato da aplicação da força física, complementando sua definição inicial de inspiração weberiana.

Pioneira no estudo da polícia, sua obra foi seguida por outros pesquisadores que continuaram a definir a polícia segundo a noção de que o que constitui o policiamento enquanto tal é a "distribuição não-negociável de força coercitiva". Dessa forma, a maioria das definições dadas por outros autores apresenta-se como variações que acrescentam alguns elementos a esse "Police Use of Force Paradigm (PUFP)" (BRODEUR, 2010), sem alterar o núcleo central da definição. Nesses casos, a ordem é substituída pelas noções de paz ou de segurança, e a legitimidade policial, algumas vezes, já não se assenta na existência do Estado, mas - como variante de certo contratualismo - na suposição de que há um consenso social a respeito da sua atuação.

Este é o caso de Robert Reiner (2004), que enfatiza o aspecto funcional e finalista da polícia sem deixar de reconhecer que ela possui autorização para o uso da força física. Reiner (2004, p. 27) a define tal como se apresenta nas sociedades modernas e relativamente complexas, como uma “[...] corporação especializada de pessoas a quem foi dada a responsabilidade básica formal da força legítima para salvaguardar a segurança". Dessa forma, compreende historicamente o mandato da polícia como o da manutenção "emergencial" da ordem - obtida, na maior parte das vezes, pela capacidade principal do uso da força.

A definição de David H. Bayley (2006), que se deduz de uma análise histórica voltada para novos padrões de policiamento, não escapa a essa lógica. A polícia, em sua compreensão, é um grupo de pessoas destinado a regular as relações interpessoais por meio da aplicação da força física, necessitando, para tanto, de autorização coletiva. No caso da polícia moderna, ela possuiria três características. Primeiro, de acordo com seu agenciamento, seria pública ou privada; em segundo lugar, seria especializada (focada no uso da força e não em outras atribuições) e, por fim, profissionalizada, ou seja, preparada para realizar funções exclusivas, ligadas ao uso da força física e exercidas com base em determinados padrões como treinamento formal, supervisão e remuneração específicos.

$\mathrm{O}$ autor que mais se distancia dessa definição instrumental da polícia é Dominique Monjardet. Em O que faz a polícia? (2012), ele apresenta ressalvas ao conceito de Bittner (2003), mas sustenta que o aspecto da força física é indissociável da polícia, acrescido da necessidade de 
conformidade social: "A polícia não é esse instrumento que intervém quando 'force may have to be used' [...], mas sim quando lhe é ordenado fazê-lo, seja por uma instância que tem autoridade sobre ela ou pelo sistema de valores partilhados aqui e agora" (MONJARDET, 2012, p. 23). Ele também ressalta que a polícia é, ao mesmo tempo, uma instituição, uma profissão com interesses, cultura e coalizações e uma organização, com sua divisão própria do trabalho, seus ofícios e sua burocracia. Contrariando indiretamente as formulações de Bayley (2006), Monjardet (2012) afirma que a aceitação social da polícia não faz com que ela seja melhor ou mais eficaz, já que ela permanece um instrumento de coerção e de vigilância. Em Estados autoritários, ela serve como instrumento de dominação; como profissão, torna-se instrumento de repressão de uma determinada classe de indivíduos entendidos como adversários ou associados, e quando aplicada a si mesma pela coletividade, passa a ser uma forma de socializar os valores predominantes.

Por sua vez, Jean-Claude Monet (2002) procura fazer um apanhado de todas as definições em Polícias e sociedades na Europa. A polícia é definida como um agrupamento humano que remete um tipo de organização burocrática, mas que possui relação direta com o poder político; por isso, para Monet (2002), a noção de polícia sempre implica em maior ou menor grau a soberania do Estado e o recurso ao uso da força, reabilitando a definição de Bittner. Ao adotar uma perspectiva histórica, expõe a ambivalência da instituição policial e as dificuldades de definir o que ela é, o que ela protege (ou seja, sua missão), sua forma de atuação e relação com o Estado.

Dessa forma, na compreensão tanto de Bayley quanto de Monjardet, o que distingue a polícia não é simplesmente o uso da força, mas a sua autorização coletiva - embora uma polícia que não goze de aceitação social não deixe, por isso, de ser uma polícia. Essa ressalva crítica é feita, entre outros, pelo canadense Jean-Paul Brodeur (2010), para quem o paradigma do uso policial da força de Bittner estaria centrado no elemento errado. Não é que a polícia não use a força; ela a usa, mas em momentos raros nas sociedades (desenvolvidas, especificaríamos nós) atuais. Porém, ao não distinguir competência e desempenho profissionais, o acento da definição de polícia não recairia no que realmente caracteriza a sua prática, a "legal lawlessness". Ou seja, a polícia é definida pelo uso de um conjunto de meios - entre os quais, a violência -, em regra, juridicamente inacessível ao resto da população.

A revisão desse corpus teórico permite perceber que após décadas, e apesar da concorrência de diversos autores dedicados ao tema, a polícia continua a ser definida (seja em razão da sua competência, desempenho, missão ou legitimidade) a partir da sua instrumentalidade em relação ao emprego da violência estatal. A essa definição, ora se agregam as características da burocratização e legalidade estatal de Weber, ora uma perspectiva democrática, que reatualiza o contratualismo. Mesmo a definição de Brodeur, que se pretende uma das mais críticas a Bittner, engasta-se na 
definição weberiana ao recorrer à noção de que o Estado e a polícia detêm o monopólio legítimo de certas atividades, como ocorre com o uso da violência.

A maior parte dos autores dos policing studies reconhece que a atividade policial não é inteiramente determinada pelo uso da força, ou que essa força é raramente empregada, constituindo mais um elemento virtual do que atual. É o caso de Bittner (2003), Bayley, (2006) e Reiner (2004) que, ao trabalharem com as tarefas da polícia, ou sua tipologia, atêm-se às atribuições administrativas e outras atividades reunidas sob as rubricas de "prestação de serviços" ou "atendimentos não-emergenciais". No entanto, quando se propõem a definir o que é a polícia, policiamento, ou o mandato policial, a definição original e weberiana de Egon Bittner permanece central. Na medida em que Monjardet ou Brodeur procuram reconhecer que a violência instrumental da polícia não seria determinante, não conseguem propor uma nova definição que ultrapasse esse paradigma, limitando-se a manter um diálogo crítico com Bittner.

Isso delimita uma lacuna teórica em potencial nos policing studies; ou, no mínimo, uma não-correspondência entre teoria e realidade. Trata-se de um indício levantando pelo próprio Bitter que, ao publicar Aspects of police work, analisava as transformações policiais incorporadas ao POP e ao policiamento comunitário. Porém, ao menos no caso brasileiro, as transformações policiais, sociais e econômicas, parecem exceder o marco teórico dos policing studies, exigindo sua integração a um novo conjunto de problemas emergentes da prática policial e de seu funcionamento na dinâmica metropolitana do capitalismo contemporâneo e dos dispositivos de controle biopolítico que as polícias passariam a incorporar.

\section{BIOPOLÍTICA, POLÍCIA E SOCIEDADES DE CONTROLE}

Pouco a pouco, os policing studies foram recepcionados no Brasil tanto por iniciativa das Universidades quanto das academias de polícia, visando especialmente à elaboração do modelo do policiamento comunitário. Dessa forma, houve uma confluência entre sua recepção e a elaboração dos primeiros planos de segurança pública nacionais, muitas vezes aliados a políticas estaduais e/ou municipais ${ }^{7}$. Em decorrência dos impasses gerados pelas modificações socioeconômicas, e da inflação discursiva sobre o crescimento vertiginoso da criminalidade, correspondente à ineficiente e excessiva violência policial, surgiram diversos programas de polícia híbridos de segurança e cidadania, como é o caso das Unidades de Polícia Pacificadora, no Rio de Janeiro, e das Unidades Paraná Seguro, no Paraná - projetadas como espelho das UPPs.

\footnotetext{
${ }^{7}$ É o caso do Plano Nacional de Segurança Pública, de 2000, e do PRONASCI, o Programa Nacional de Segurança Pública com Cidadania, de 2007.
} 
A principal inovação realizada por esses programas consiste na introdução do policiamento comunitário, cuja fórmula, modos de operação e diretrizes não dispõem de consenso, mas que estariam assentados sobre a ideia de que a própria comunidade (ou seja, aqueles que são vigiados, controlados e regulados pela polícia) torne-se parte integrante na manutenção da segurança pública (SKOLNICK; BAYLEY, 2006). O policiamento comunitário representa um ponto de intersecção entre o discurso criminológico sobre a delinquência, o discurso sociológico sobre a polícia e seus desdobramentos socioeconômicos. Assim, o policiamento, mesmo em sua versão comunitária, não seria capaz de resolver ou suavizar os problemas da criminalidade nas cidades brasileiras; isso exigiria a concorrência de políticas públicas de cunho social e econômico voltadas ao desenvolvimento da cidadania, principalmente nas "zonas quentes" das periferias brasileiras.

Esses eram os vetores definidores do policiamento comunitário quando foi lançado o Programa Paraná Seguro no ano de 2012, tendo por principal iniciativa a implantação das Unidades Paraná Seguro. O modelo de uma polícia repressiva seria integrado ao modelo preventivo do policiamento comunitário nas regiões de alta criminalidade nas principais cidades paranaenses (em uma versão que recebeu o nome de "UPS-Segurança") e a ele seriam articulados programas e atividades sociais para atender às vulnerabilidades sociais encontradas nas comunidades (em sua versão "UPS-Cidadania”) (SESP-PR, 2016).

Assim, uma polícia-repressão era deslocada por uma polícia bioeconômica. Isso, no entanto, não significa que se tenha substituído um paradigma policial por outro, mas que é possível verificar a emergência de traços de um novo modelo de policiamento que passou a coexistir e se integrar ao primeiro. Esse deslocamento torna o quadro de análise dos policing studies e sua corrente definição de polícia, que chamamos de "polícia-repressão", insuficiente, o que exige que os traços configuradores desse modelo emergente possam ser descritos, fornecendo elementos para a elaboração de um novo modelo.

Como esse deslocamento se dá, e qual o significado de uma polícia biopolítica? Apesar de ser comumente definida a partir de seus traços negativos e repressivos, a polícia não é um instrumento exclusivo de violência. A revisão de sua gênese histórica e europeia, que nos legou o modelo policial, permite perceber que a polícia nasce de uma autorregulação social (FOUCAULT, 2011) posteriormente institucionalizada pelo Estado, em correlação com a emergência de tecnologias de poder de controle biopolítico das populações (FOUCAULT, 2008b).

Genealogicamente, a polícia se desenvolve como um dispositivo social que será progressivamente institucionalizado pelo Estado, atuando em rede com diversas formas de poder, de modo que as transformações sociais operam adaptações no dispositivo policial, ao mesmo tempo em que o dispositivo policial interfere nos arranjos e dinâmicas sociais. Há, portanto, uma 
correspondência genealógica entre o social e o policial, não apenas porque a polícia pontilha uma dada sociedade com intervenções, mas porque a própria sociedade pode assumir uma forma policial - isto é, antagônica à política, se acompanharmos o binômio forjado por Jacques Rancière (1996, p. 44$)^{8}$. O que faz com que coloquemos entre parênteses a sociologia weberiana dos policing studies é, em primeiro lugar, que antes de sua estatização e profisssionalização, a polícia nomeou por muito tempo uma série de mecanismos positivos de regulação social que não implicavam necessariamente uma lógica repressiva, mas positiva e constitutiva do corpo social. A emergência da polícia como instituição encontra-se intimamente ligada ao advento do biopoder, como fenômeno de transformação dos dispositivos de poder (FOUCAULT, 2008b).

Durante os anos 1970, Michel Foucault insistiu na recusa do poder como uma matéria exclusivamente repressiva - como o poder configurado nas soberanias modernas; sua analítica descobria que o poder pode atuar de maneira constitutiva, positiva, a partir do momento em que disciplina corpos individuais ou regula fenômenos de população, produzindo tanto subjetivações quanto realidades de massa. A positividade da biopolítica das populações consiste em sua tendência "a produzir forças, a fazê-las crescer e a ordená-las mais do que a barrá-las, dobrá-las ou destruílas" (FOUCAULT, 2015b, p. 146), como resultado do aparecimento progressivo do capitalismo. Assim, a biopolítica é uma forma de poder que se interessa diretamente pelo homem enquanto ser vivente, enquanto espécie, procurando maximizar suas forças (FOUCAULT, 2008a e 2008b).

A polícia integra a racionalidade biopolítica ao lado de um conjunto de mecanismos de segurança, como os dispositivos típicos, geralmente de natureza securitária e previdenciária, que constituem o welfare state. Sua origem remonta aos fenômenos de urbanização europeus e de capitalização da riqueza em mercadorias, ligados ao desenvolvimento do capitalismo industrial. A partir do desenvolvimento do modelo policial inglês e francês, Foucault (2008b e 2015a) mostra que a polícia tinha atribuições diretamente relacionadas às questões urbanas, como regulação da circulação de pessoas e mercadorias, da saúde coletiva, da moralidade civil e religiosa, de modo que a criminalidade era apenas uma de suas muitas atribuições. Com a profissionalização da polícia, durante os séculos XVIII e XX, seu escopo é progressivamente reduzido até se transformar na

\footnotetext{
8 "A polícia pode ser dócil e amável", afirma Rancière, parecendo fazer eco ao Deleuze (2013) do "Pós-escrito sobre as sociedades de controle". "Continua sendo, mesmo assim, o contrário da política, e convém circunscrever o que cabe a cada uma delas. É assim que muitas questões tradicionalmente repertoriadas como questões da moral e da política só tratam, a rigor, das relações da moral e da polícia. Saber, por exemplo, se todos os meios são bons para assegurar a tranquilidade da população e a segurança do Estado é uma questão que não depende do pensamento político - o que não significa que não possa fornecer o lugar de uma intervenção transversal da política. É assim também que a maior parte das medidas que nossos grupos e laboratórios de 'reflexão política' imaginam para mudar ou renovar a política aproximando o cidadão do Estado ou o Estado do cidadão oferece, na verdade, à política a sua mais simples alternativa: a da simples polícia. Pois é uma figuração da comunidade própria à polícia aquela que identifica a cidadania como propriedade dos indivíduos passível de se definir numa relação de maior ou menor proximidade entre o seu lugar e o do poder público." (RANCIÈRE, 1996, p. 44-45).
} 
instituição responsável pela manutenção da ordem, por meio do uso da violência como instrumento de repressão à criminalidade. O que essa redução evidencia é que, originalmente, a polícia não se identificava com um dispositivo de violência de tipo negativo ou repressor; ela constituía, antes, um dispositivo regulatório da vida urbana tal como essa se processava em larga escala, segundo os cortes macropolíticos dos fenômenos de população.

Todavia, a partir da década de 1950, o modelo repressivo e negativo a que a polícia havia sido progressivamente reduzida passaria a ser questionado, impulsionado pelos processos de globalização e mutação do capitalismo e pelas reações das populações policiadas correlatas a esses processos (explosões de criminalidade, greves sindicais etc.). Isso tornou possível não um retorno à racionalidade biopolítica original, mas a reemergência adaptada às novas transformações do capitalismo de alguns de seus traços genealógicos, impondo à polícia as tarefas próprias de um agente bioeconômico das metrópoles.

Essas transformações são catalisadas pelo desenvolvimento do biocapitalismo (NEGRI, 2015, p. 57-58) e das sociedades de controle (DELEUZE, 2013; LAZZARATO e NEGRI, 2013); isto é, por sociedades caracterizadas por uma reestruturação cognitiva do capitalismo produtivo que já não está espacial e temporalmente adstrita ao regime de exploração disciplinar própria dos meios de confinamento fabril e disciplinar, mas cujas estratégias de exploração imaterial, simbólica, afetiva e informacional passam a atravessar transversalmente a totalidade do campo social (NEGRI e HARDT, 2004, p. 22; BERARDI, 2005, p. 35).

No Brasil, o modelo repressivo de policiamento só começou a ser repensado em função de diretrizes mais preventivas, comunitárias e não militarizadas após a redemocratização, ocorrida no fim década de 1980. A grande mudança estrutural que tornou possível o aprofundamento dessa nova lógica só foi intensificada a partir do fim dos anos 2000, gerando alterações estratégicas na atuação policial. Essas transformações devem ser lidas como transformações próprias ao biopoder. A partir da segunda metade do século XX, no contexto do pós-guerra, o encerramento que caracterizava as sociedades disciplinares enfrentou crises contínuas - crise da prisão, da fábrica, da família (DELEUZE, 2013; LAZZARATO e NEGRI, 2013) e, por sua vez, da própria polícia como dispositivo de controle.

Essas crises, que se estendem a todos os dispositivos de poder então vigentes, são sintomas dos movimentos de resistência ao modelo do panopticon (COCCO, 2009), nos quais estão incluídos a luta antimanicomial, as explosões de criminalidade que envolvem minorias, as greves do movimento operário etc. As resistências a esses dispositivos de poder conheceram como réplica a instauração de novos dispositivos que implicam a difusão insidiosa e generalizada dos mecanismos de controle (mecanismos de segurança) e a difusão ampliada da lógica disciplinar por toda a 
sociedade. Trata-se do que Gilles Deleuze (2013) denominou de sociedades de controle, ao analisar as últimas obras de Foucault que, a exemplo do curso Nascimento da biopolítica (2008a), manifestam essas transformações do poder.

Em nossas sociedades, o controle transfigura-se em um sistema de modulações que se aplica mais em gerir a vida do que em suprimi-la, seguindo as mutações do capitalismo pós-Segunda Guerra Mundial, dirigindo-a a partir da racionalidade do próprio mercado. Os paradigmas da soberania e da disciplina serão integrados ao do governo. A correlação entre biopolítica e economia se altera, uma vez que a relação com a vida passa a ser outra. Na medida em que as relações de produção já não fabricam apenas mercadorias, mas formas de vida (DELEUZE, 2013; COCCO, 2009), é possível dizer que as sociedades ingressam na lógica de governo da bioeconomia, ou do biocapitalismo. A vida passa a ser investida não apenas nos cálculos do poder e do Estado (biopolíticos), mas também nos cálculos econômicos e do mercado (bioeconômicos).

Nas sociedades de controle, a relação de sujeição ao poder também se altera, na medida em que sua lógica é afetada pelas formas emergentes de organização do trabalho que escapam à materialidade e à territorialidade da fábrica, passando a fundar-se em aspectos imateriais como a cooperação e autonomia. O poder passa a funcionar ancorado na produção de subjetividades (ou formas de vida), constituindo aí no novo terreno da exploração e da libertação (COCCO, 2014). A multiplicidade dos homens torna-se passível de controle e regulação a partir do tempo em si mesmo, na medida em que o trabalho imaterial - entendido como trabalho cognitivo, afetivo, comunicativo e técnico-científico - emerge como forma hegemônica de trabalho (NEGRI e HARDT, 2004), sem que o trabalho material e fabril desapareça. Já não se trata mais apenas dos corpos adestrados e fabricados pelas disciplinas, mas das próprias subjetividades constituías nesse processo como elementos configuradores de valor. Na medida em que o capital investe a totalidade da sociedade, o conjunto da vida humana individual e social é posto a trabalhar (LAZZARATO, 1999; LAZZARATO e NEGRI, 2013).

Se o econômico tende a colonizar e investir a vida por completo, já não basta reprimir ou vigiar, mas governar controladamente a população como um todo ou em suas unidades decompostas (as “comunidades"). O princípio dessa racionalidade de controle consiste no elemento econômico, ou seja, os investimentos no trabalho e em um meio aberto - muito além dos muros das instituições disciplinares de confinamento. Os resultados desse governo econômico da vida como chave de transformação das práticas policiais resumem-se, de um lado, à transformação do discurso sobre a criminalidade e, de outro, à crise do dispositivo policial, exigindo novas formas de análise que considerem a articulação das tecnologias de segurança e controle, e das renovadas formas de integração das tecnologias de soberania e disciplinares. 
O discurso sobre a criminalidade se transforma. A partir do século XVIII, a análise estatística alterava a forma de conceber o crime e o criminoso ao expor sua normalidade endêmica (FOUCAULT, 2008b). Já no século XX, a análise econômica da criminalidade postulava que o crime não é fruto da irracionalidade humana; o criminoso passa a ser compreendido como um sujeito que opera escolhas racionais por meio de um cálculo de utilidade. A partir desse momento, o criminoso se tornava também um homo oeconomicus, e o crime passa a ser interpretado segundo a racionalidade neoliberal como um ato que, uma vez cometido, acarreta ao indivíduo o risco da pena. O crime se explica, então, por um cálculo de utilidade individual pelo qual o criminoso em potencial avalia a relação de custo-benefício da conduta criminosa (FOUCAULT, 2008a).

No entanto, é a crise do dispositivo policial, e sua necessária adaptação à lógica do exercício de poder nas sociedades de controle, que conduz a uma polícia bioeconômica. Nessa nova configuração, não apenas os efeitos dos poderes soberano, disciplinar ou necropolítico (MBEMBE, 2018) persistem, mas compõem-se com a nova necessidade de regulação do social em um espaço aberto, por meio de controles mais insidiosos e, aparentemente, mais brandos, que incidem nos efeitos econômicos e de valor das relações sociais. Nas sociedades de controle, as relações sociais e econômicas não se estabelecem segundo formas rígidas, a partir de cortes definidos no espaçotempo do trabalho produtivo espoliado nas fábricas; seu regime de funcionamento obedece à lógica da virtualidade fluída do trabalho cognitivo ou imaterial e ao espaço-tempo aberto, virtualmente ilimitado, controlado de maneira reticular e contínua (BERARDI, 2005, p. 53), de modo que a totalidade do campo social passa a ser o esteio da produção de valor. Trabalho e emprego, produção e assalariamento, tornam-se realidades disjuntas e independentes (LAZZARATO, 2011, p. 12): no capitalismo cognitivo, e em seu paradigma de plena atividade (Idem, p. 38), todos trabalham, mas nem todos são assalariados.

O panopticon, modelo ideal das sociedades disciplinares, implicava a territorialização e o controle externo, que fixa os indivíduos em instituições de encerramento como escolas, usinas, hospitais, prisões etc. Trata-se de um modelo adequado ao capitalismo fabril. Em contrapartida, nas sociedades de controle, os mecanismos de segurança e suas formas próprias de regulação, tornamse imanentes ao tecido social, mobilizando as subjetividades, modulando-as, adaptando-as ao capitalismo especulativo e financeirizado.

Isso permite compreender por que, a partir da década de 1960, assistimos ao crescimento do discurso sobre a crise da polícia no Ocidente. Constituído como um agente externo de intervenção no corpo social, o funcionamento do dispositivo policial sempre oscilou entre estratégias soberanas de repressão e disciplinares, de controle. No entanto, com a explosão de muitas formas de criminalidade a partir dessa década em países como Estados Unidos, Inglaterra e 
França, muitas vezes ligada aos problemas sociais como o movimento negro e operário, a resposta policial deu-se, em grande parte, como repressão, com um uso abusivo da violência.

Isso deflagrou discursos sobre a necessidade de remodelar do dispositivo policial, e se tornou objeto de estudo dos policing studies que, ao mesmo tempo em que criticavam a ação violenta e ineficiente da polícia, procuravam formas de estabelecer na prática os critérios para um novo modelo policial. Uma das formas que passou a ser difundida foi o modelo do policiamento comunitário, cujo principal slogan consiste em convocar a própria comunidade à tarefa policial.

No Brasil, esse discurso se intensificou com a redemocratização, no final da década de 1980, e com as transformações na composição econômico-social do país vividas entre as décadas de 1990 e a primeira década dos anos 2000. A racionalidade neoliberal colonizou pouco a pouco os discursos e as práticas governamentais, influenciando a atuação policial que, agora, ao menos no caso das Unidades Paraná Seguro, conjuga o modelo soberano-disciplinar com um trabalho bioeconômico, que faz da polícia um dos principais canais a partir dos quais essa racionalidade governamental pode ser estendida ao conjunto da população.

\section{AS UNIDADES PARANÁ SEGURO: UMA POLÍCIA BIOECONÔMICA}

A primeira década dos anos 2000, no Brasil, foi marcada por um crescimento econômico vertiginoso e pelo aumento de índices como o PIB e o IDH, além da diminuição da desigualdade em termos de renda (IBGE, 2014 e 2017). Conjuntamente com essas mudanças, os índices de criminalidade cresceram de forma expressiva, fazendo, por exemplo, com que algumas cidades brasileiras apresentassem taxas de homicídios equivalentes às de localidades com guerra civil (FBSP, 2012; 2014; 2016). Isso gerou a necessidade de ressituar as discussões a respeito da segurança pública, com a progressiva adoção do policiamento comunitário.

Essas transformações também colocaram em questão a centralidade dos pobres no contexto do capitalismo cognitivo 9 , em toda a sua ambivalência. Giuseppe Cocco (2014, p. 162), por exemplo, demonstrou como a centralidade dos pobres torna-se o terreno de um conflito a partir da emergência de uma nova classe média brasileira, a chamada "classe C", e como sua emergência deflagrou uma disputa econômica sobre essa população e os territórios periféricos que ela ocupa.

\footnotetext{
${ }^{9} \mathrm{O}$ capitalismo cognitivo, de acordo com Moulier-Boutang (2011, p. 57), pode ser compreendido como: “a mode of accumulation in which the object of accumulation consists mainly of knowledge, which becomes the basic source of value, as well as the principal location of the process of valorisation. Issues, such as property rights, positioning in networks, alliances and project management become major institutional and organisational factors. Their role is crucial. The strategies of this capitalism are determined by the quest for a spatial, institutional and organisational positioning likely to increase its capacity for engaging in creative processes and for capturing their benefits". Ele ainda esclarece que é dentro desse modo de acumulação que o trabalho imaterial se torne hegemônico e que vida e trabalho se indeterminam.
} 
Essa centralidade dos pobres é fruto tanto das novas relações de produção que incluem os pobres como tais (ou seja, enquanto pobres) quanto das políticas sociais adotadas pelos governos desse período, que investiram em ações de redistribuição de renda e redução de desigualdades em um horizonte neodesenvolvimentista ${ }^{10}$ (COCCO, 2014). Durante esses anos, em decorrência de um processo que já se desencadeava a partir da década de 1990, as relações de trabalho sofrem uma reconfiguração que impactou, sobretudo, as classes mais pobres, aumentando seu poder de compra e, também, a grade de inteligibilidade pelo qual essas classes eram tradicionalmente compreendidas. Trata-se de estratos sociais comumente concebidos no Brasil como classes de indivíduos marginalizados e excluídos, moradores de periferias e favelas das cidades, vítimas do desemprego e reféns da criminalidade. Sua caracterização como "classe média emergente", como proletariado cognitivo metropolitano ou "precariado" (BRAGA, 2017), correlaciona-se com o deslocamento da hegemonia do trabalho material para o imaterial, em cujo modelo já não existe um "lado de fora" da produção social onde manter os excluídos. É nesse sentido que Cocco (2014) salienta que "a periferia vai para o centro e o centro vai para a periferia", formando aquilo que ele define como "um não-lugar sem fora".

Nos países ocidentais desenvolvidos, o advento do capitalismo cognitivo implica a relativização das regras do mercado de trabalho - consistente com os fenômenos de terceirização (aumento absoluto e relativo do setor de serviços), terciarização (hegemonia do trabalho precário, temporário, doméstico e autônomo) e aumento dos estabelecimentos sem empregador, sob a lógica do empreendedorismo -, em paralelo com o processo de desmantelamento do welfare. Giuseppe Cocco (2014, p. 17) descreveu esse processo como a "brasilianização da Europa"11 e de outras partes do mundo, uma vez que essas características já se encontravam presentes no Brasil como parte da sua posição subalterna no capitalismo industrial mundial (COCCO e NEGRI, 2005).

Por sua vez, a globalização do capital e, portanto, dessa forma de biocapitalismo, instaurase no Brasil a partir de um processo que é, na verdade, uma europeização ancestral, que remonta à Colônia; não se pode falar nem de um desmantelamento de um welfare state nem da emergência das formas de trabalho precário "porque não se pode destruir aquilo que não existe". Assistiríamos, na verdade, a um desmantelamento da própria classe média a partir da generalização dessas condições de trabalho típicas da pobreza. Nos dois casos, a população não é simplesmente regulada para fazer as forças do Estado cresceram, mas torna-se um recurso à disposição das empresas e, como tal, faz das políticas sociais implementadas pelo Estado-empresa formas de maximizar a utilidade da população por meio do aumento da empregabilidade e da produção, diminuindo os

\footnotetext{
${ }^{10}$ A título de exemplo, o Programa Bolsa Família e a democratização do acesso ao ensino superior por meio das cotas raciais, mas também do PROUNI e do FIES, entre outros programas.

${ }^{11}$ Sobre o uso do termo brasilianização, ver em especial o primeiro capítulo de (COCCO, 2009).
} 
custos como um todo, por meio do enfraquecimento do poder dos sindicatos, da degradação da legislação trabalhista, do achatamento do valor das aposentadorias e da precarização da proteção social.

Essas condições estruturais constituem o pano de fundo para a emergência de um novo tipo de subjetividade laboral, baseada no modelo da empresa. Em termos práticos, a generalização do modelo do trabalhador-empresário supõe (1) a disjunção entre trabalho produtivo e emprego assalariado, (2) a "desestruturação do salário global" que livra o capitalista dos custos indiretos do trabalho, (3) a identificação psicológica do trabalhador com sua função como "a missão existencial que a sociedade lhe confiou" e (4) um contínuo autogoverno ficcionalizado como autonomia laboral pelo qual é levado a se portar como "o guarda de si mesmo" (BERARDI, 2005, p. 31) A concorrência passa a ser a forma das relações sociais fundadas na gestão das desigualdades (LAZZARATO, 2011, p. 14), que serão reproduzidas e moduladas por discursos e ações incidentes sobre os riscos de que essa nova sociedade se tornou portadora: seria melhor ter um emprego precário do que estar desempregado, por exemplo (DARDOT e LAVAL, 2016). Mas, como essa reconfiguração do capitalismo e, também do próprio Estado, se relacionam com o papel da polícia? Qual o papel da polícia em programas como o das Unidades Paraná Seguro, que faz com que ela se integre às novas formas de gestão capitalista da população e à "centralidade" dos pobres?

O ponto nevrálgico está no fato de que a emergência de novas formas de inclusão da pobreza - ou dos excluídos - vai muito além da formação de um simples "exército de reserva", tornando os pobres centrais em uma bioeconomia capitalista. Os pobres podem ser incluídos a partir da própria pobreza, sem mudar sua significação. O espaço urbano ocupado pelos pobres tornou-se objeto de disputas pelo capital, de forma que os problemas que cercam as periferias e favelas ingressam na cena biocapitalista como novas possibilidades de exploração, através daquilo que é mais comum à multidão dos pobres: suas redes de cooperação social e cognitiva (BERARDI, 2005, p. 35), a autovalorização do trabalho - ainda que essa intervenção seja feita em nome do combate à criminalidade, o que deveria soar como um indício de que a relação entre capitalismo, subjetivação e violência se altera.

O caso das Unidades de Polícia Pacificadora no Rio, como forma mais emblemática e modelo inaugural para Unidades Paraná Seguro, representa muito bem essa correlação entre polícia e bioeconomia. As novas formas capitalistas demandavam um novo sistema de gerência dos ilegalismos - já que o tráfico armado e outras formas de criminalidade obstavam circulação e produção do capital -, para justamente incluir aqueles territórios e contingentes populacionais em mercados específicos - imobiliário, telefonia, serviços, bancos, consumo etc. A ocupação militar e 
policial aparece, portanto, como uma "inclusão forçada" para a mobilização produtiva desses territórios (COCCO, 2011).

O caso das Unidades Paraná Seguro em Curitiba parece distender a lógica das UPPs cariocas com a ocupação policial de territórios-chave da cidade, caracteristicamente periféricos. A partir de 2012, foram instaladas 10 unidades em Curitiba. O cronograma iniciou-se em março com a implantação da UPS no bairro Uberaba. Em seguida, foi implantada uma UPS no bairro Parolin e quatro UPS, no mês e julho, na Cidade Industrial (nas regiões da Vila Sabará, Via Verde, Vila Nossa Senhora da Luz e Vila Caiuá). Em agosto, foi instalada a UPS da Vila Osternack (no bairro Sítio Cercado) e em setembro a quinta UPS na Cidade Industrial, na Vila Sandra. Por fim, em outubro, as últimas UPS's foram estabelecidas nas Vilas Ludovica, no Tatuquara, Vila Trindade no Cajuru e, segundo consta em alguns relatórios consultados, a UPS Vila Torres, no bairro Rebouças. As dez unidades seguiram as etapas traçadas na Diretriz 002/2012 e em 2013 já começava a operar as atividades das duas vertentes do projeto (PARANÁ, 2017).

$\mathrm{Na}$ cidade de Curitiba, os últimos vinte ou trinta anos foram marcados pelo mesmo crescimento vertiginoso do país, seja em termos de renda, seja em termos de criminalidade. Desde a década de 1990, o crescimento econômico deu-se de forma quase contínua, apresentando aumento de índices como PIB e IDH, além do aquecimento do setor terciário (IBGE, 2014 e 2017). Por mais que tenha havido crescimento da indústria entre os anos de 2011 e 2015, o peso relativo do setor terciário quase triplicou em todos os bairros da cidade, com especial destaque para aqueles que receberam as UPSs. Esses bairros demonstraram durante os anos de 2011 a 2015 um crescimento relativamente alto do setor terciário (tabela 01), especialmente quando se considera que essas regiões são majoritariamente compostas por uma população com uma renda média mensal por domicílio de R\$2.927,27 (classe “C”, ou inferior), conforme dados do IBGE para 2010.

\begin{tabular}{|c|c|c|c|c|c|c|c|c|}
\hline \multirow[t]{3}{*}{ REGIÃO } & \multicolumn{8}{|c|}{ SETORES ECONÔMICOS } \\
\hline & \multicolumn{2}{|c|}{ Indústria } & \multicolumn{2}{|c|}{ Comércio } & \multicolumn{2}{|c|}{ Serviços } & \multicolumn{2}{|c|}{ Total } \\
\hline & 2011 & 2015 & 2011 & 2015 & 2011 & 2015 & 2011 & 2015 \\
\hline Bairro Novo (Sítio Cercado) & $\begin{array}{c}1.33 \\
4\end{array}$ & $\begin{array}{c}2.34 \\
9\end{array}$ & 3.695 & 4.936 & 2.075 & 3.526 & 7.116 & $\begin{array}{c}10.82 \\
6\end{array}$ \\
\hline $\begin{array}{llll}\text { Cajuru } & \text { (Uberaba } & \text { e } & \text { Vila } \\
\text { Trintade) } & & & \\
\end{array}$ & $\begin{array}{c}2.35 \\
1\end{array}$ & $\begin{array}{c}3.77 \\
3\end{array}$ & 7.542 & 8.852 & 5.741 & 8.590 & $\begin{array}{c}15.72 \\
8\end{array}$ & $\begin{array}{c}21.31 \\
7\end{array}$ \\
\hline CIC & $\begin{array}{c}1.86 \\
6\end{array}$ & $\begin{array}{c}3.33 \\
3\end{array}$ & 3.733 & 5.368 & 2.743 & 5.017 & 8.395 & $\begin{array}{c}13.77 \\
2\end{array}$ \\
\hline
\end{tabular}




\begin{tabular}{|l|c|c|c|c|c|c|c|c|}
\hline Matriz & 4.98 & 6.44 & 23.44 & 24.90 & 35.39 & 44.82 & 64.40 & 76.83 \\
7 & 5 & 5 & 8 & 5 & 7 & 2 & 8 & 7 \\
\hline Portão (Parolin) & 3.42 & 3.65 & 13.02 & 11.59 & 12.27 & 14.86 & 28.94 & 30.33 \\
& 7 & 1 & 5 & 7 & 8 & 9 & 4 & 4 \\
\hline Tatuquara (V. Ludovica) & - & 1.26 & - & 2.380 & - & 1.331 & - & 4.982 \\
\hline
\end{tabular}

TABELA 1 - Número de estabelecimentos econômicos formais em Curitiba por regiões que abrigam o perímetro das Unidades Paraná Seguro nos anos de 2011 e 2015.

Fonte: Elaborado pelos autores com dados do SMF/Cadastro de liberação de alvarás e Agência Brasil (2017).

Nota: sem dados para o bairro Tatuquara durante o ano de 2011.

Essas informações, no entanto, devem ser analisadas em conjunto com as taxas de desocupação em Curitiba. Apesar da diminuição do número de empregos formais para os anos de 2011 a 2015 (cf. tabela 02), a taxa de desocupação permaneceu baixa, em torno de 5\%, se comparada ao aumento sofrido no país, que chegou a ser maior que 10\% (Observatório do Trabalho/DIEESE, 2011; 2013; 2015), indicando que não houve um simples aumento do desemprego, mas sim que ele foi acompanhado pela precarização das atividades laborais.

\begin{tabular}{|l|l|l|l|}
\hline $\begin{array}{l}\text { ANO/M } \\
\text { ES }\end{array}$ & $\mathbf{2 0 1 1}$ & $\mathbf{2 0 1 3}$ & $\mathbf{2 0 1 5}$ \\
\hline $\begin{array}{l}\text { Fevereir } \\
\text { o }\end{array}$ & 4.534 & 3.654 & -27 \\
\hline Março & 2.933 & 3.404 & 896 \\
\hline Abril & 4.681 & 3.938 & -2.224 \\
\hline Maio & 2.853 & 1.860 & -1.439 \\
\hline Junho & 1.863 & 330 & -3.590 \\
\hline Julho & 1.962 & -1.544 & -4.237 \\
\hline Agosto & 5.032 & 1.044 & -2.947 \\
\hline $\begin{array}{l}\text { Setembr } \\
\text { o }\end{array}$ & 4.960 & 4.526 & -2.527 \\
\hline Outubro & 3.948 & 549 & -2.946 \\
\hline $\begin{array}{l}\text { Novembr } \\
\text { o }\end{array}$ & 3.544 & 610 & -1.132 \\
\hline
\end{tabular}




\begin{tabular}{|l|l|l|l|}
\hline Dezembr & - & - & - \\
o & 7.861 & 11.18 & 12.25 \\
& & 4 & 4 \\
\hline TOTAL & 28.44 & 7.186 & - \\
& 9 & & 32.42 \\
& & & 6 \\
\hline
\end{tabular}

TABELA 2 - Evolução do número de empregos formais em Curitiba ao longo dos anos 2011, 2013 e $2015^{*}$

Fonte: Elaborado pelos autores com bases nos dados do Observatório do Trabalho/DIEESE/Curitiba, (2011; 2013; 2015).

Nota: $(*)$ : Excetuados os meses de janeiro por falta de dados.

Com o crescimento econômico, sobrevieram diversas políticas de estímulo ao consumo e ao empresariado a partir dos anos 2000 - como subsídios fiscais para empresas, redução de impostos nas compras de determinadas mercadorias, incentivos a pequenos e microempreendedores e investimentos em educação voltada para a qualificação tecnológica, tanto em nível federal como estadual $^{12}$. A capital paranaense seguiu o mesmo ritmo de crescimento das taxas de criminalidade no país, chegando ao patamar de quase 40 homicídios para cada 100 mil habitantes em 2011. A taxa era maior que a média do Estado, que para o mesmo ano foi de 29,3, e maior que a média registrada no Estado do Rio de Janeiro no mesmo ano, na casa de 24,9 hom./100 mil habitantes (FBSP, 2012).

Diante desse quadro, as UPSs foram propostas pelo Governo do Estado do Paraná, partindo de uma retórica voltada para a redução das taxas de criminalidade - em especial dos homicídios aliado ao discurso de implantação de políticas socioeconômicas que serviriam para reduzir a “vulnerabilidade" da população (SESP-PR, 2016). Trata-se, portanto, de uma política híbrida, que une segurança e cidadania. O desenho da UPS-Segurança inspirou-se no modelo do policiamento comunitário como forma supostamente democrática de policiar. Diante de uma crise da polícia no país - cumulada ao funcionamento comumente "repressivo" desse aparato -, a forma comunitária funciona como modo de legitimar a violência exercida, seja por meio de mecanismos mais imanentes ao tecido social (colocando, e.g., a comunidade no centro das discussões sobre a segurança pública), fomentando certo autocontrole comunitário, ou por meio de técnicas mais "suaves" de gestão - mas nem por isso menos eficazes -, como é o caso da visitação casa a casa que muitas vezes envolvia vistorias.

\footnotetext{
${ }^{12}$ No Estado, algumas dessas iniciativas foram o Programa Bom Negócio e o Paraná Competitivo que, ainda em execução, incentivam particulares e Municípios visando ao aquecimento da economia no Estado.
} 
No entanto, essa vertente apresentou também o aspecto mais conhecido da polícia, como expressão do monopólio legítimo da violência pelo Estado, na medida em que o processo de implantação das Unidades seguiu um modelo de ocupação quase bélico, com o cerco e congelamento de áreas. A megaoperação que envolveu essas implantações mobilizou grande parte do contingente policial, tanto da Polícia Militar (e suas diversas ramificações, como BOPE e Cavalaria) quanto da Polícia Civil e da Guarda Municipal (INFORM. n. 003/2017 - $1^{\circ}$ CRPM). O sistema de congelamento das áreas remete à ideia de uma guerra para ocupação de um território que é ao mesmo tempo físico e virtual; não se trata apenas de determinados espaços urbanos ocupados por essas comunidades, mas de uma disputa pelo governo biopolítico dos pobres que compõem a chamada "classe C", como Giuseppe Cocco (2011) afirmou a respeito do Rio de Janeiro.

$\mathrm{O}$ exercício da soberania torna-se uma condição necessária à instalação de estratégias de controle bioeconômico, denotando um novo tipo de funcionamento das tecnologias de poder tipicamente soberanas, agora a serviço de objetivos biopolíticos e econômicos. O perímetro bloqueado torna-se o locus de uma zona de exceção: ninguém entra ou sai sem passar pela polícia e apresentar sua identidade. Para operacionalizar essa estratégia de congelamento, algumas das implantações contaram com até mil policiais e realizaram centenas de prisões, detenções e apreensões de drogas e armamentos (INFORM. n. 003/2017 - $1^{\circ} \mathrm{CRPM}$ ).

$\mathrm{Na}$ vertente da UPS-Cidadania, concentram-se as funções bioeconômicas da polícia. Ainda que suas iniciativas tenham sido geralmente idealizadas como atividades extra ou parapoliciais, na prática, as ações de desenvolvimento dessa política mobilizaram o uso das Unidades Paraná Seguro e de seu contingente policial. As ações envolveram as três esferas de governo (federal, estadual e municipal) a partir da atuação de Secretarias, mas também de parcerias com agentes privados - com destaque para FIEP/SESI/SENAI, sistemas voltados para o mercado. Suas propostas de atuação basearam-se em um trabalho de diagnóstico realizado pelos próprios policiais, preparando terreno para os processos de inclusão subordinada que se seguiriam: um trabalho no cerne biopolítico das comunidades que de forma alguma se relaciona com as expressões policial-repressivas, mas com uma espécie de mecanismo de diagnose-segurança que cartografa as demandas por inclusão.

Esse mapeamento prévio constatou vinte e dois problemas nas comunidades vistoriadas, sendo que a maioria dizia respeito a questões econômicas como "baixa qualificação para o empreendedorismo", "baixo desenvolvimento socioeconômico local" e "informalidade nos empreendimentos", apontando que as preocupações iam muito além da proposta original de diminuir os números de homicídios (TCT n $n^{\circ}$ 001/2013-SEJU). Poucos problemas diagnosticados referiam-se à segurança propriamente dita como a "violência em lugares públicos", "desintegração na ação da estrutura de segurança", "drogadição" e "prostituição infantil”. Alguns desses 
problemas, como a drogadição e a prostituição, dizem respeito mais à saúde e à desigualdade do que à segurança (embora sejam comumente associados a problemas de segurança pública).

Como resposta, um amplo espectro de ações e programas, ações continuadas e feiras de serviços, foram estabelecidos e firmados mediante Termo de Cooperação Técnica e, como espelho do diagnóstico, apenas alguns deles diziam respeito à segurança pública em sentido estrito. É o caso da criação da patrulha escolar, do PROERD (Programa Educacional de Resistência às Drogas) e das APADs (Associações de Prevenção, Atenção e Reinserção Social de Usuários e Dependentes de Drogas), que deveriam ser promovidos pela SEJU ou pela SESP, do policiamento comunitário, que seria realizado pelos policiais militares, e da oferta de cursos sobre esse tipo de policiamento (TCT n ${ }^{\circ} 001 / 2013-$ SEJU).

No entanto, a maioria dos programas referia-se às áreas da educação e do trabalho, intervindo sobre a gestão do capital humano daquelas comunidades. $\mathrm{Na}$ área de educação, giravam em torno da qualificação profissional para jovens e adultos, incluindo-se apenados e adolescentes em cumprimento de medidas socioeducativas ${ }^{13}$. Na área do trabalho, foram propostos programas de estímulo ao empreendedorismo, como também cadastros de emprego, habilitação de seguro desemprego, emissão de CTPS e programas de microcrédito (como o Bom Negócio Paraná ou o Fomento Paraná, este por meio do Banco Empreendedor).

Registraram-se, também, ações voltadas ao urbanismo, como manutenção do sistema de iluminação pública, limpeza de ruas e, ainda, remoção de moradias irregulares. Neste último aspecto, o projeto previa a regularização, ou reassentamento, de cerca de 7.000 unidades, havendo informações sobre de um parcial reassentamento, no primeiro semestre de 2013 (CURITIBA, 2013). Por fim, registraram-se atividades voltadas para o esporte e o lazer, além de serviços pontuais de órgãos públicos como SANEPAR, COPEL e PROCON (feiras, atendimento ao consumidor e emissão de documentos pessoais, e.g.), além das parcerias com instituições privadas como FIEP/SESI/SENAI, associações de moradores etc. ${ }^{14}$

\footnotetext{
${ }^{13}$ Como incentivo e criação de programas como o Programa Escola Aberta, PRONATEC, escolas integrais, medidas de reinserção social de apenados mediante educação, qualificação profissional e trabalho e cursos de capacitação para pessoas acima de dezesseis anos (nos Liceus de Ofício, CRAS) e disponibilização de vagas de trabalho para adolescentes em cumprimento de medidas socioeducativas, além da instalação de Telecentros/Espaço Cidadão, com o fim de oferecer cursos de qualificação, inclusão digital e acesso a serviços eletrônicos do governo.

${ }^{14}$ Do escopo extenso de atividades e programas propostos, pouco foi efetivamente realizado pela vertente UPSCidadania, e em grande medida as ações executadas concentram-se nos anos de 2013 a 2015. Existem somente relatórios para esse período (excetuando-se o relatório de 2016 que apenas contabiliza em números os atendimentos e serviços prestados, sem especificá-los). Trata-se das atividades das feiras de serviços e de apenas alguns dos programas propostos dentro das ações continuadas. Algumas das propostas consistiam na oferta de orientações jurídicas sobre os direitos humanos em geral, mas efetivamente focaram-se em direitos do consumidor, da criança e do adolescente e da mulher (no caso de violência doméstica) - embora tenham sido realizadas em alguns colégios as atividades da "Árvore da atitude", que mobilizam as metas do milênio e, portanto, os direitos humanos como um todo (SEJU, 2016).
} 
Entre os anos de 2013 e 2016 (anos para os quais havia dados disponíveis), foram realizadas quatorze feiras, que totalizaram cerca de sessenta mil atendimentos. Suas principais atividades concentravam-se nos atendimentos ao consumidor, confecção de documentos, habilitação para o seguro-desemprego, captação de vagas de trabalho, entre outras atividades voltadas para o esporte e lazer, e atividades próprias com as empresas públicas de infraestrutura, como a SANEPAR (tratamento de água e abastecimento) e a COPEL (iluminação pública e fornecimento de energia elétrica) (CURITIBA, 2013; SEJU, 2015; 2016).

De acordo com os relatórios da PMPR e da SEJU (relatórios gerais), e com entrevista realizada com o Ten. Coronel Rothenburg (2017), durante o período de instalação das unidades em 2012, e no ano subsequente, os policiais realizaram diversas apreensões de drogas, armas, prisões em flagrantes, entre outras operações. Além desse aspecto propriamente policial, o efetivo militar empregado nas UPSs estava envolvido continuamente, mesmo após o encerramento do programa em 2015, em atividades comunitárias muito heterogêneas, como visitas aos moradores, palestras e apoio do contingente às atividades propostas, como as feiras de serviços.

Esse conjunto de atividades e programas atuam diretamente sobre as condutas dos indivíduos incentivando-os ao trabalho, ao empreendedorismo, ao endividamento (microcrédito) e à busca pela qualificação profissiona ${ }^{15}$. Propostos em torno de práticas de polícia comunitária,

\footnotetext{
${ }^{15}$ Essas iniciativas exprimem um conjunto de ações que recobrem todo o terreno da produção biopolítica dessas comunidades, abrangendo do emprego e do assalariamento às iniciativas da economia informal e do empreendedorismo individual. A educação empreendedora aliada à abertura de linhas de microcrédito para empreendedores exprime uma forma clara de inclusão subordinada à dinâmica do capitalismo cognitivo, na medida em que exprime a relação entre trabalho biopolítico e capitalismo financeiro por meio da forma de subjetivação do trabalhador-empresário e de sua inclusão dos circuitos bancários da dívida. Se Maurizio Lazzarato (2017, p. 205) estiver correto em afirmar que a relação entre credor e devedor no capitalismo rentista exprime uma relação de poder, temos aí o perfeito e claro exemplar de uma atuação bioeconômica da polícia: a que suscita, incentiva, estimula, conduz e governa comportamentos sociais de inclusão subordinada do trabalho biopolítico, inclusive pelo mecanismo financeiro do endividamento como condição do trabalho-empresa. Tanto a inclusão pelo consumo como pela renda são capturadas pela subordinação ao dispositivo de poder e de extração de mais trabalho biopolítico do endividamento.
}

\title{
BIOECONOMIC POLICE: STUDYING THE CASE OF THE POLICING APPARATUS ON PARANÁ SEGURO UNITS
}

\begin{abstract}
This paper describes the police as a bioeconomic apparatus of power. Based on documental research, the article advances that argument by scrutinizing the case of Paraná Seguro Units (UPS), a public security program which took place in Curitiba, Brazil, between 2012 and 2015. On one hand, analyzing the UPS program allowed us to extend the weberian boundaries of policing studies, which commonly reduces policing logics to a repressive and negative version of power exercise. On the other hand, the socioeconomic governmental initiatives which came along with UPS and police acting suggested a non-repressive and constitutive model of power as an emergent policing logics. In the analysed case the policing practices were assembled to urban, social and labor reconfigurations, indicating correspondences among the functionings of power and control apparatuses and biocapitalism. Documental and empirical findings were evaluated through Foucauldian and post-Foucauldian theoretical categories leading to rethink the police as a bioeconomic apparatus of power.
\end{abstract}


Keywords: Police. Bioeconomy. Biocapitalism. Societies of control. Paraná Seguro Units.

\section{REFERÊNCIAS}

AGAMBEN, Polícia soberana. In: Meios Sem Fim: notas sobre a política. Belo Horizonte: Autêntica Editora, 2015, p. 97-100.

AGÊNCIA CURITIBA. Perfil econômico das regionais em Curitiba. Curitiba, jan. 2017. Disponível em: $<$ http://www.agencia.curitiba.pr.gov.br/>. Acesso em: 14 set. 2018.

BAYLEY, David. H. Padrões de Policiamento: uma análise internacional comparativa. Tradução de Renê Alexandre Belmonte. 2a. ed., 1a reimp. São Paulo: EDUSP, 2006.

BERARDI, Franco (Bifo). A fábrica da infelicidade: trabalho cognitivo e new economy. Tradução de Orlando dos Reis. Rio de Janeiro: DP\&A, 2005.

BITTNER, Egon. Aspectos do Trabalho Policial. Tradução de Ana Luísa Amêndola Pinheiro. São Paulo: EDUSP, 2003.

The functions of the police in modern society: a review of background factors, current practices, and possible role models. Maryland: National Institute of Mental Health: 1970.

BRASIL. Lei n. 11.530, de 24 de outubro de 2007. Institui o Programa Nacional de Segurança Pública com Cidadania - PRONASCI e dá outras providências. Diário Oficial da União, Brasília, 24 out. 2007. Disponível em: <http://www.planalto.gov.br/ccivil_03/_ato20072010/2007/Lei/L11530.htm>. Acesso em: 14 set. 2018.

Plano Nacional de Segurança Pública. Brasília, 2000. Disponível em: $\overline{<\mathrm{http}: / / w w w . o b s e r v a t o r i o d e s e g u r a n c a . o r g / f i l e s / P N S P \% 202000 . p d f>. ~ A c e s s o ~ e m: ~} 14$ set. 2018.

BRAGA, Ruy. A pulsão plebeia. Trabalho, precariedade e rebeliões sociais. São Paulo: Alameda, 2014. . A rebeldia do precariado. Trabalho e neoliberalismo no Sul global. São Paulo: Boitempo, 2017.

BRODEUR, Jean Paul. The Policing Web. Oxford University Press, 2010.

CRARY, Jonathan. 24/7: capitalismo tardio e os fins do sono. Tradução de Joaquim Toledo Jr. São Paulo: Ubu Editora, 2016.

COCCO, Giuseppe. Korpobraz: por uma política dos corpos. Rio de Janeiro: Mauad X, 2014.

La guerra di Rio de Janeiro: l’offensiva del capitalismo cognitivo. Uninomade 2.0. 9. jan. 2011. Disponível em: $<$ http://www.ihu.unisinos.br/noticias/40005-a-guerra-no-rio-dejaneiro-a-ofensiva-do-capitalismocognitivo>. Acesso em: 14 set. 2018.

Mundobraz: o devir-mundo do Brasil e o devir-Brasil do mundo. Rio de Janeiro: Record, 2009.

; NEGRI, Antonio. Glob(Al). Biopoder e lutas em uma América Latina globalizada. Tradução de Eliana Aguiar. São Paulo: Record, 2005.

CURITIBA, Defesa Social. Relatório UPS desenvolvimento e cidadania - $1^{o}$ semestre 2013. 29 out. 2013. Disponível em: <http://www.paranaemacao.pr.gov.br/arquivos/File/relatorio.pdf>. Acesso em: 09 fev. 2019.

DARDOT, Pierre; LAVAL, Christian. A nova razão do mundo: ensaios sobre a sociedade neoliberal. Tradução de Mariana Echalar. SP: Boitempo, 2016. 
DIEESE, Departamento Intersindical de Estatística e Estudos Socioeconômicos/Observatório do Trabalho. Boletim do Emprego Formal em Curitiba, Curitiba, 2011. Disponível em: <http://curitiba.dieese.org.br/producoestecnicas.php>. Acesso em: 14 set. 2018.

$\overline{\text { em: } 14}$ set. 2018

Curitiba, 2013. Disponível em: <http://curitiba.dieese.org.br/producoestecnicas.php>. Acesso em: 14 set. 2018

Curitiba, 2015. Disponível em: <http://curitiba.dieese.org.br/producoestecnicas.php>. Acesso

DELEUZE, Gilles. Conversações (1972-1990). Tradução de Peter Pál Pelbart. 3. ed. São Paulo: Editora 34, 2013.

FBSP, Fórum Brasileiro de Segurança Pública. 2012, São Paulo. Anuário... São Paulo: 2012. Disponível em: $<\mathrm{http}$ ://www.forumseguranca.org.br/produtos/anuario-brasileiro-desegurancapublica/8o-anuario-brasileiro-deseguranca-publica $>$. Acesso em: 14 set. 2018.

2014, São Paulo. Anuário... São Paulo: 2014. Disponível em: $\overline{<\mathrm{http}: / / w w w . f o r u m s e g u r a n c a . o r g . b r / s t o r a g e / 8 ~ a n u a r i o ~} 2014$ 20150309.pdf>. Acesso em: 14 set. 2018.

2016, São Paulo. Anuário... São Paulo: 2016. Disponível em: <http://www.forumseguranca.org.br/wpcontent/uploads/2017/01/Anuario_Site_27-01-2017RETIFICADO.pdf $>$. Acesso em: 14 set. 2018.

FOUCAULT, Michel. A Hermenêutica do Sujeito: curso no Collège de France (19811982). Tradução de Marcio Alves da Fonseca e Salma Tannus Muchail. 2a. ed. São Paulo: Martins Fontes, 2006.

. A Sociedade Punitiva: curso no Collège de France (1972-1973). Tradução de Ivone C. Benedetti. São Paulo: WMF Martins Fontes, 2015a.

A verdade e as formas jurídicas. 3. ed. Tradução de Roberto Machado et al. Rio de Janeiro: NAU, 2011.

História da Sexualidade I: a vontade de saber. Tradução de Maria Thereza da Costa Albuquerque e J. A. Guilhon Albuquerque. 2a. ed. São Paulo: Paz e Terra, 2015b.

História da Sexualidade III: o cuidado de si. Tradução de Maria Thereza da Costa Albuquerque e J. A. Guilhon Albuquerque. 1a. ed. São Paulo: Paz e Terra, 2014.

Nascimento da Biopolítica: curso no Collège de France (1978-1979). Tradução de Eduardo Brandão. São Paulo: Martins Fontes, 2008a.

Segurança, território, população: curso no Collège de France (1977-1978). Tradução de Eduardo Brandão. São Paulo: Martins Fontes, 2008b.

GOLDSTEIN, Herman. Policiando uma Sociedade Livre. Tradução de Marcello Rollemberg e Maria Cristina P. da Cunha Marques. São Paulo: EDUSP, 2003.

Improving Policing: a problem-oriented approach. Crime and Delinquency, v. 25, n. 1336, p. 236-258, abr. 1979. Univ. of Wisconsin Legal Studies Research, Wisconsin, EUA. Disponível em: $<$ https://ssrn.com/abstract=2537955>. Acesso em: 14 set. 2018.

HAN, Byung-Chul. Sociedade do cansaço. Tradução de Enio Paulo Giachini. Petrópolis: Vozes, 2015.

IBGE, Instituto Brasileiro de Geografia e Estatística. Censo Demográfico de 2010.

Disponível em: <www.ibge.gov.br>. Acesso em: 06 fev. 2019.

Produto Interno Bruto dos Municipios 2012: contas nacionais n. 43. Rio de

Janeiro, 2014. Disponível em:

$<$ http://ftp.ibge.gov.br/Pib_Municipios/2012/pibmunic2012.pdf>. Acesso em: 06 fev. 2019. 
Produto Interno Bruto dos Municípios 2010-2015: contas nacionais n. 58. Rio de Janeiro, 2017. Disponível em:

$<$ https://biblioteca.ibge.gov.br/visualizacao/livros/liv101458.pdf>. Acesso em: 06 fev. 2019.

LAZZARATO, Maurizio; NEGRI, Antonio. Trabalho Imaterial: formas de vida e produção da subjetividade. Tradução de Monica de Jesus Cesar. 2ª ed. Rio de Janeiro: Lamparina, 2013.

. O governo das desigualdades: crítica da insegurança neoliberal. Tradução de Renato Abramowicz Santos. São Carlos: EdUFSCAR, 2011.

Para uma definição do conceito de "bio-política". Lugar Comum, Rio de Janeiro, n. 5-6, p. 81-96, jan. 1999. Disponível em: <http://uninomade.net/wpcontent/files_mf/111712121250lugar_comum_5-6.pdf $>$. Acesso em: 14 set. 2018.

MBEMBE, Achille. Crítica da razão negra. Tradução de Sebastião Nascimento. São Paulo: n-1 edições, 2018.

. Necropolítica. Biopoder, soberania, estado de exceção, política da morte. Tradução de Renata Santini. São Paulo: n-1 edições, 2018.

MONET, Jean-Claude. Polícias e sociedades na Europa. Tradução de Mary Amazonas Leite de Barros. 1a. ed., São Paulo: EDUSP, 2002.

MONJARDET, Dominique. O que faz a Polícia: sociologia da força pública. Tradução de Mary Amazonas Leite de Barros. São Paulo: EDUSP, 2012.

MOULIER-BOUTANG, Yann. Cognitive capitalism. Translated by Ed Emery. Cambridge/UK: Polity Press: 2011 .

NEGRI, Antonio. Biocapitalismo. Tradução de Marcia Paula Gurgel Ribeiro. 1 a. ed., São Paulo: Iluminuras, 2015.

; HARDT, Michael. O Trabalho de Dionísio: para a crítica ao Estado pós-moderno. Tradução de Marcello Lino. Juiz de Fora, MG: Editora UFJF-Pazulin, 2004.

NERI, Marcelo (Coord). A nova classe média: o lado brilhante dos pobres. Rio de Janeiro: CPS/FGV, 2010. Disponível em: < https://www.cps.fgv.br/ibrecps/ncm2010/NCM_Pesquisa_FORMATADA.pdf $>$. Acesso em: 14 set. 2018.

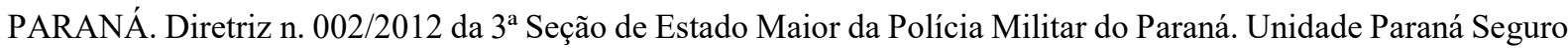
- UPS. Curitiba, 30 de abr. 2012 (documento reservado).

Diretriz n. 004/2012 da $3^{\text {a }}$ Seção de Estado Maior da Polícia Militar do Paraná. Unidade Paraná Seguro UPS. Curitiba, 02 de mar. 2012 (documento reservado).

Decreto Estadual n. 8.306 de 24 de maio de 2013. Institui, no âmbito das Unidades Paraná Seguro, o Programa de Ações Integradas de Desenvolvimento e Cidadania - UPS - Cidadania, cria o seu Comitê Gestor, o Grupo Técnico de Execução e dá outras providências. Diário Oficial do Estado do Paraná n. 8.965, Curitiba, 24 maio 2013. Disponível em: $<$ http://www.legislacao.pr.gov.br/legislacao/pesquisarAto.do?action=exibir\&codAto=95484 $>$. Acesso em: 14 set. 2018.

Informação n. 003/2017 do $1^{\circ}$ Comando Regional - 3a Secção de Estado Maior da Polícia Militar do Paraná. Curitiba, 16 out. 2017.

Lei n. 16.582 de 29 de setembro de 2010. Institui, no âmbito do Estado do Paraná, o Projeto Paraná em Ação, a ser desenvolvido pelo Poder Executivo, conforme especifica. Diário Oficial do Estado do Paraná n. 8.314, $\begin{array}{lllll}\text { Curitiba, } & 29 & \text { set. } & 2010 . & \text { Disponível }\end{array}$ $<$ http://www.legislacao.pr.gov.br/legislacao/pesquisarAto.do?action=exibir\&codAto $=56279 \&$ indice $=1 \&$ totalRegistros $=1>$. Acesso em: 14 set. 2018 . 
denotam que o policiamento pode ser a expressão operacional de um modelo de gestão bioeconômica. O policiamento comunitário legitima a violência e a repressão policiais através de um discurso democrático, além de possibilitar formas de controle mais insidiosos, difusos, para e

Lei n. 18.377 de 15 de dezembro de 2014. Instituição, no âmbito do Estado do Paraná, do Programa de Ações Integradas de Desenvolvimento e Cidadania em áreas, cujas comunidades se encontram em situação de vulnerabilidade social. Diário Oficial do Estado do Paraná n. 9.356, Curitiba, 15 fev. 2014. Disponível em: $<$ http://www.legislacao.pr.gov.br/legislacao/pesquisarAto.do?action=exibir\&codAto $=134556$ \&indice $=1 \&$ totalRegistros=1>. Acesso em: 14 set. 2018.

- Termo de Cooperação Técnica $n^{0}$ 001/2013. Secretaria de Estado da Justiça, Cidadania e Direitos Humanos. 14 de janeiro $2013 . \quad$ Disponível $<$ http://www.paranaemacao.pr.gov.br/arquivos/File/Termocuritiba_1.pdf>. Acesso em: 14 set. 2018.

POCHMANN, Márcio. Nova classe média? O trabalho na base da pirâmide social brasileira. Sâo Paulo: Boitempo, 2012.

RANCIÈRE, Jacques. O desentendimento: política e filosofia. Tradução de Ângela Leite Lopes. São Paulo: Editora 34, 1996.

REINER, Robert. A política da polícia. Tradução de Jacy Cardia Ghirroti e Maria Cristina Pereira da Cunha Marques. São Paulo: EDUSP, 2004.

ROTHENBERG, Ten. Cor. Vanderley. Entrevista I. [out. 2017]. Entrevistador: Karoline Coelho de Andrade e Souza. Curitiba, 2017. 1 arquivo .m4a (39.24 min.)

SESP-PR. Secretaria de Segurança Pública e Administração Penitenciária do Paraná. Unidade Paraná Seguro. Disponível em: <http://www.seguranca.pr.gov.br/modules/conteudo/conteudo.php?conteudo=89>. Acesso em: 14 set. 2018 .

SEJU, Secretaria de Justiça, Trabalho e Direitos Humanos do Paraná. Paraná em Ação. Disponível em: $<$ http://paranaemacao.pr.gov.br>. Acesso em: 14 set. 2018.

Relatório síntese de atividades 2015. 18 fev. 2016. Disponível em:

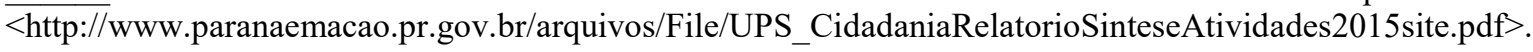
Acesso em: 08 fev. 2019.

Relatório sintese de atividades 2016. 18 dez. 2016. Disponível em:

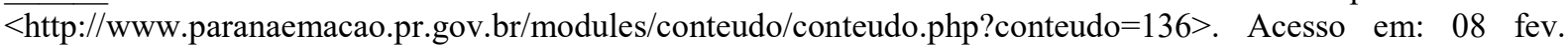
2019.

SKOLNICK, Jerome H. Justice without trial: law enforcement in democratic society. 4a. ed. New Orleans, Luisiana: Quid Pro Books, 2011.

; BAYLEY, David H. Policiamento comunitário: questões e práticas através do mundo. Tradução de Ana Luiza Amêndola Pinheiro. São Paulo: EDUSP, 2006.

SOUZA, Jessé de. Os batalhadores brasileiros. Nova classe média ou nova classe trabalhadora? Belo Horizonte: Editora UFMG, 2012.

WEBER, Max. Ciência e Política: duas vocações. São Paulo: Cultrix, 1972.

Economia e sociedade: fundamentos da sociologia compreensiva (vol. 2). Tradução de Regis Barbosa e Karen Elsabe Barbosa. Brasília, DF: Editora Universidade de Brasília; São Paulo: Imprensa Oficial do Estado de São Paulo, 2004. 
extrapoliciais e com uma roupagem cidadã: a inclusão dos pobres nas redes do capitalismo cognitivo.

A noção de "cidadania" foi chave para a proposição de uma série de novos programas e atividades, articulados a uma gama de outros já existentes (como o PRONATEC e o Bom Negócio Paraná) que, ao invés de apresentar uma relação com a noção tradicional de cidadania, relacionavam-se diretamente com os mecanismos integradores do biocapitalismo. Eis o que confirma o desempenho de funções bioeconômicas pela polícia, na medida em que esta se torna um meio para a ativação e execução do controle sobre os fluxos metropolitanos de desejo, trabalho, produção de valor, atividade livre e iniciativa, comportamento sócio-econômico, subjetividade etc. Ao invés de esses controles e mecanismos permanecerem difusos, talvez pouco permeáveis, as demandas topológicas por segurança nos bairros e vilas mais pobres tornaram possível que a polícia, integrada à esfera da vida cotidiana com roupagem comunitária, se tornasse veículo e o mecanismo agregador de estratégias biopolíticas e de sujeição capitalista, especificamente direcionadas aos territórios urbanos e à composição social e de subjetividade das classes "C" e inferiores.

Assim, a polícia e seus controles biocapitalistas "passam para dentro", são interiorizados sob a forma de um autogoverno. Um dos aspetos mais importantes da noção do "empreendedor de si", proposta por Dardot e Laval (2016), e que permeia toda política voltada para o empreendedorismo, é que o homem-empresa é aquele que tem, acima de tudo, zelo pela própria segurança. Se esse empreendedor vê a si mesmo como um capital que merece receber investimentos, na mesma medida deve ser objeto de sua autopreservação. Trata-se daquilo que Foucault (2006 e 2014) denominou de "cuidado de si", de "ascese", mas como se fosse seu duplo falsificado. Pela óptica neoliberal do homem-empresa, o cuidado de si torna-se o móvel do próprio exercício do poder, procurando internalizar nos indivíduos os controles e as interdições necessárias. Sua espessura subjetiva, no entanto, já não é o efeito das belas-almas que internalizam os "nãos" das disciplinas. Antes, a subjetividade neoliberal parece constituir a expressão tanto de um neoescravismo ecumênico, globalizado pelas formas avançadas do trabalho precarizado em escala mundial (MBEMBE, 2018, p. 19-20) e do endividamento global (LAZZARATO, 2017, p. 205), como da internalização de um "sim", de uma positividade de performance esgotante e autoimposta, própria das sociedades de desempenho (HAN, 2015, p. 24-25) e de sua experiência de temporalidade 24/7 (CRARY, 2016, p. 19)

Isso permite compreender como se articulam os investimentos de poder efetuados tanto no nível dos indivíduos - como são os incentivos à educação, à qualificação profissional, ao cuidado da saúde, à escalada do "capital humano" das comunidades biopolíticas das grandes metrópoles -, 
quanto a roupagem do policiamento comunitário que, em uma escala mais ampla, mobiliza a comunidade para internalização desses novo regime de subjetividade.

Nesses termos, as práticas da polícia, hoje, são da ordem de um agir comutativo entre soberania e biopoder, na medida em que um requer sempre o outro para poder funcionar. A polícia não abandonou o caráter repressivo de uma "polícia soberana", como quisera Giorgio Agamben (2015); não deixou de ser um dispositivo capaz de uma violência ímpar, de exercer o direito de gládio soberano contra o corpo social, movendo-se continuamente no terreno da fluido da exceção. Mas a polícia tornou-se, ao lado disso, um agente de bioeconomia das cidades, atuando inclusivamente para subsumir a totalidade da vida social às novas dinâmicas do capital, gerenciando a criminalidade, mas também os processos de subjetivação sob um ponto de vista bioeconômico.

\section{CONSIDERAÇÕES FINAIS}

Embora o programa revele uma realidade nova - a da polícia bioeconômica -, é necessário reconhecer que a análise de seus efeitos é parcial, diante de pelo menos duas circunstâncias limitadoras. A primeira delas consiste no fato de que o programa não apenas criou atividades e políticas novas, mas, sobretudo, integrou-as a outras já existentes, mas pouco articuladas nas esferas municipal, estadual e federal, de modo a produzir aplicações locais de estratégias de poder mais globais e difusas. A segunda, diz respeito à escassez de informações para integral verificação desses efeitos, seja em razão da descontinuação do programa, ou em virtude da brevidade de sua duração, seja em função da inexistência de registros, ou da impossibilidade de acesso a informações mantidas pelos órgãos públicos envolvidos.

Ainda assim, os principais resultados corroboram a hipótese de que, muito além de um simples aparato repressivo do Estado, a polícia passou a ser um mecanismo de segurança e de gestão das populações a serviço de uma racionalidade governamental de caráter bioeconômico. Sua presença em territórios-chave de diversas cidades brasileiras, a exemplo de Curitiba ou do Rio de Janeiro, promove a inclusão de territórios e populações inteiras na lógica do capitalismo cognitivo contemporâneo.

Com a hegemonia do trabalho imaterial e as transformações de toda a lógica econômicosocial que a acompanham, as disciplinas encontram-se, agora, difusas por toda a extensão do corpo social. No espaço aberto e virtualmente ilimitado das sociedades de controle, os dispositivos biopolíticos passam integrar a anátomo-política dos corpos à biopolítica das populações, gerenciando a vida em sua totalidade e determinando o advento de novos padrões de policiamento. As formas de policiamento soft analisadas pelos policing studies - como são o POP e o policiamento comunitário, este utilizado nas UPS - podem ser interpretados como mutações policiais subsumidas 
a essa lógica gerencial, o que supõe que as formas de poder se tornem imanentes ao próprio tecido social e, por isso mesmo, mais insidiosas, sutis, mas não menos violentas. Ao mesmo tempo em que as polícias continuam a ser forças-tarefa do poder soberano ou operar estratégias de poder necropolíticas, impregnam as comunidades para governá-las horizontalmente, desde baixo, operando como um dispositivo de otimização e saturação bioeconômicas, atuando localmente a partir de uma racionalidade global, biocapitalista.

Essa inclusão forçada dos pobres nas malhas do capitalismo cognitivo não consiste apenas em compelir ao trabalho - tarefa de que as disciplinas cumpriam bem desde o século XVIII -, mas favorecer a extração de valor de uma produção imaterial ininterrupta; criar e modular subjetividades, cérebros, formas de vida e de existência sutil e eficazmente. A presença policial na articulação de políticas híbridas de segurança-cidadania induz, incita e estimula a constituição de condutas e comportamentos econômicos, difunde como meio homogêneo de subjetivação um homem-empresa que, crendo no cuidado de si e na autopromoção, torna-se o empregado de si mesmo, precarizado e desprovido de direitos. Trata-se de uma sutileza imaginada para uma política pública que visa à promoção da cidadania e a redução da criminalidade, mas que inoculam e racionalizam uma ordem social dobrada à exploração capitalista do cognitariado metropolitano, garantindo a produção de formas de vida entrelaçadas com a economia e nascida de seus dispositivos de controle e regulação.

Assim, embora a abordagem dos policing studies continue válida - especialmente em países de capitalismo periférico, em que a polícia jamais deixou de ser um aparelho de repressão -, sua ênfase tânato ou necropolítica deixa escapar elementos que denotam o exercício de um poder bioeconômico das polícias sobre as populações. É o caso das Unidades Paraná Seguro, que escapam aos grandes cortes analíticos weberianos na medida em que suas estratégias não são redutíveis aos quadros largos demais do modelo da repressão soberana.

\section{NOTAS}

Trabalho recebido em 15 de setembro de 2018

Aceito em 14 de fevereiro de 2019 